КОНТРОЛЬ

ДЕЯТЕЛЬНОСТИ ПОЛИЦИИ

А.Ю. Винокуров

DOI: 10.7256/2222-1964.2013.3.7998

\title{
ПРОКУРОРСКИЙ НАДЗОР ЗА ИСПОЛНЕНИЕМ ЗАКОНОВ ПОЛИЦИЕЙ: ПРЕДМЕТ И ПРЕДЕЛЫ ОСУЩЕСТВЛЕНИЯ
}

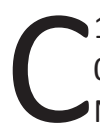
1 марта вступил в силу Федеральный закон от 07.02.2011 № 3-Ф3 «О полиции» (далее - Закон № 3-Ф3) ${ }^{1}$, ст. 52 которого определено, что надзор за исполнением полицией законов осуществляют Генеральный прокурор РФ и подчиненные ему прокуроры в соответствии с федеральным законодательством. Предложенная законодателем формулировка при всей ее стереотипности и, казалось бы, очевидности нуждается в пояснениях.

Во-первых, о какой сфере надзора за исполнением законов идет речь? В этом смысле любопытной представляется позиция, изложенная в справочноинформационной системе «КонсультантПлюс», отсылающая применительно к федеральному законодательству, в соответствии с которым подразумевается осуществление надзора за исполнением законов полицией, к гл. 3 Раздела III Федерального закона от 17.01.1992 № 2202-1 «О прокуратуре Российской Федерации» (далее - Закон о прокуратуре)², регламентирующей предмет такой отрасли прокурорского надзора как надзор за исполнением законов органами, осуществляющими оперативно-розыскную деятельность, дознание и предварительное следствие. К слову, в ст. 30 Закона о прокуратуре, посвященной полномочиям прокурора в рассматриваемой сфере, закреплено, что таковые устанавливаются уголовно-процессуальным законодательством РФ и другими федеральными законами. То есть в отношении оперативно-розыскной деятельности и предварительного расследования, осуществляемых органами полиции, прокуроры руководствуются отнюдь не рамками Закона о прокуратуре, а положениями соответственно Федерального закона от 12.08.1995 № 144-Ф3 «Об оперативно-розыскной деятельности» и Уголовно-процессуального кодекса РФ от 18.12.2001 № 174-Ф3.

\footnotetext{
${ }^{1}$ СЗ РФ. - 2011. - № 7. - СТ. 900 (с послед. изменениями).

2 СЗ РФ. - 1995. - № 47. - Ст. 4472 (с послед. изменениями).
}

С точки зрения дословного толкования ст. 52 Закона № 3-Ф3 напрашивается вывод о проверке прокурорами исполнения полицией любых законов, в том числе регулирующих сферы общественных отношений, не связанных с оперативно-розыскной или процессуальной деятельностью. При этом необходимо отметить, что аналогичная законодательная конструкция использована в ст. 44 Федерального закона от 28.12.2010 № 403-Ф3 «О Следственном комитете Российской Федерации» (далее - Закон о СК) ${ }^{3}$, согласно которой «надзор за исполнением законов Следственным комитетом осуществляют Генеральный прокурор РФ и подчиненные ему прокуроры в соответствии с полномочиями, предоставленными федеральным законодательством». В отношении процитированной нормы нами высказывалась позиция о допустимости осуществления надзора за исполнением законов за рамками процессуальной деятельности следственных органов и их должностных лиц ${ }^{4}$, которая в последующем была подтверждена в августе 2011 г. Главным государственно-правовым управлением Администрации Президента России в связи с запросом Генерального прокурора РФ Ю.Я. Чайки. Смысл ответа заключался в том, что анализ действующего законодательства позволяет сделать вывод о возможности применения прокурорами надзорных полномочий за рамками процессуальной деятельности Следственного комитета РФ. Правда, при этом оговаривалась допустимость осуществления непроцессуального надзора за соблюдением прав и свобод человека и гражданина, чего ст. 44 Закона о СК явно не предусматривает. Позднее при подготовке проекта будущего организационно-распорядительного документа по этому вопросу разработчики пытались закрепить

\footnotetext{
3 СЗ РФ. - 2011. - № 1. - Ст. 15 (с послед. изменениями).

${ }^{4}$ См.: Винокуров А.Ю. Следственный комитет как объект прокурорского надзора // Вестник Академии Генеральной
} прокуратуры РФ. - 2011. - № 1 (21). 
«правозащитные» надзорные позиции прокуратуры, однако с учетом высказанных рецензентами, в том числе и нами, замечаний в изданном в итоге приказе разногласия с нормами закона устранены ${ }^{5}$.

В контексте сказанного правомерен вопрос о том, а имеется ли необходимость издания применительно к надзору за исполнением законов полицией соответствующего организационно-распорядительного документа. По нашему мнению, в этом нет необходимости в силу ряда причин. Во-первых, очевиден статус Министерства внутренних дел РФ как федерального органа исполнительной власти, который в силу положений тех же ст. ст. 21 и 26 Закона о прокуратуре априорно поднадзорен прокурорам, в то время как Следственный комитет РФ имеет особый статус «федерального государственного органа» и в Законе о прокуратуре не упоминается вовсе ${ }^{6}$. Во-вторых, в отличие от Следственного комитета РФ, у которого предварительное следствие выступает фактически единственной функцией, полиция обладает многофункциональностью, в силу чего прописать в одном документе ключевые аспекты надзора за исполнением ей законов проблематично.

Вместе с тем, возвращаясь к исследуемому вопросу, необходимо затронуть еще один нюанс формулировки ст. 52 Закона № 3-Ф3. Речь идет о некорректности использования законодателем словосочетания «надзор за исполнением полицией законов», поскольку нормативно не дается даже дефиниции, позволяющей понять, что же представляет собой полиция, а ее характеристика выводится через совокупность перечисленных в ст. 2 Закона № 3-ФЗ основных направлений деятельности. Ранее мы более детально обращали внимание на это обстоятельство ${ }^{7}$. То есть правильнее было бы вести речь о надзоре за исполнением законов органами полиции и их должностными лицами.

Говоря о пределах надзора за исполнением законов полицией, очевидно, необходимо исходить из за-

${ }^{5}$ См.: приказ Генерального прокурора РФ от 09.02.2012 № 39 «Об организации прокурорского надзора за деятельностью Следственного комитета Российской Федерации вне уголовно-процессуальной сферы» // Законность. - 2012. - № 4.

${ }^{6}$ По имеющейся у автора настоящей статьи информации депутатами Государственной Думы ФС РФ В.А. Поневежским, Р.Д. Курбановым и А.Е. Хинштейном внесен проект федерального закона «О внесении изменений в Федеральный закон «О прокуратуре Российской Федерации», касающийся дополнения ст. 1, 21 и 26 положениями о поднадзорности Следственного комитета РФ во внепроцессуальной сфере.

7 См.: Винокуров А.Ю. Объекты и субъекты прокурорского надзора: проблемы законодательной идентификации // Вестник Академии Генеральной прокуратуры РФ. - 2011. - № 3 (23). конодательной взаимосвязи ст. 2 и 52 Закона № 3-Ф3, то есть обусловливать возможность применения прокурорами полномочий с проверкой ими исполнения законов при реализации таких направлений деятельности как:

1) защита личности, общества, государства от противоправных посягательств;

2) предупреждение и пресечение преступлений и административных правонарушений;

3) выявление и раскрытие преступлений, производство дознания по уголовным делам;

4) розыск лиц;

5) производство по делам об административных правонарушениях, исполнение административных наказаний;

6) обеспечение правопорядка в общественных местах;

7) обеспечение безопасности дорожного движения;

8) контроль за соблюдением законодательства РФ в области оборота оружия;

9) контроль за соблюдением законодательства РФ в области частной детективной (сыскной) и охранной деятельности;

10) охрана имущества и объектов, в том числе на договорной основе;

11) государственная защита потерпевших, свидетелей и иных участников уголовного судопроизводства, судей, прокуроров, следователей, должностных лиц правоохранительных и контролирующих органов, а также других защищаемых лиц;

12) осуществление экспертно-криминалистической деятельности.

Поскольку специальных публикаций прокурорских и иных авторов по затрагиваемой в настоящей статье проблематике нами не выявлено, обратимся к позиции по рассматриваемому вопросу, излагаемой в комментариях к Федеральному закону "О полиции». Так, в одном из таких изданий отмечается, что «предметом прокурорского надзора являются соблюдение полицией, ее должностными лицами прав и свобод человека и гражданина, установленного порядка регистрации заявлений и сообщений о преступлениях и административных правонарушениях, выполнения ОРМ, проведения дознания, а также законность решений, принимаемых должностными лицами полиции»8. Анализ приведенной формулировки позволяет увидеть в ней безусловные черты схожести с нормой ст. 29 Закона о прокуратуре, определяющей

\footnotetext{
${ }^{8}$ См.:АврутинЮ.Е.,БулавинС.П.,СоловейЮ.П., ЧерниковВ.В. Комментарий к Федеральному закону «О полиции» (постатейный). - М.: «Проспект», 2012.
} 
предмет надзора за исполнением законов органами, осуществляющими оперативно-розыскную деятельность, дознание и предварительное следствие. При этом авторы комментария справедливо исключили из собственной версии предмета надзора предварительное следствие, поскольку в перечне основных направлений деятельности полиции (ст. 2 Закона 3 №-Ф3) таковое не значится. Также правильным представляется упоминание о должностных лицах полиции, которые собственно и реализуют полномочия в рамках осуществления закрепленных за ними направлений полицейской деятельности.

Правомерным является и включение в предмет надзора законности осуществления административно-юрисдикционной деятельности ${ }^{9}$, однако ограничивать эту сферу лишь вопросами соблюдения установленного порядка регистрации заявлений и сообщений об административных правонарушениях едва ли логично, поскольку административно-юрисдикционный процесс выходит далеко за рамки собственно указанных действий, а в п. 5 основных направлений деятельности прямо называются производство по делам об административных правонарушениях и исполнение административных наказаний. И в данном вопросе предмет надзора корреспондирует ст. 24.6 Кодекса РФ об административных правонарушениях (далее - КоАП РФ), установившей, что «Генеральный прокурор Российской Федерации и назначаемые им прокуроры осуществляют в пределах своей компетенции надзор за соблюдением Конституции Российской Федерации и исполнением действующих на территории Российской Федерации законов при производстве по делам об административных правонарушениях, за исключением дел, находящихся в производстве суда ${ }^{10}$.

Как видно из процитированной формулировки статьи КоАП РФ, отраженный в ней предмет прокурорского надзора ограничивается сферой производства по делам об административных правонарушениях, не затрагивая вопросы реализации Раздела V Кодекса, регламентирующего исполнение постановлений по делам об административных правонарушениях. Налицо

\footnotetext{
9 Хотя ссылку при этом в комментарии на Закон о прокуратуре следует признать необоснованной, поскольку в данном законодательном акте указанная сфера правоотношений специально не выделяется. В ст. 22 Закона о прокуратуре лишь упоминается о праве прокурора освобождать своим постановлением лиц, незаконно подвергнутых административному задержанию на основании решений несудебных органов.

${ }_{10}$ Кодекс РФ об административных правонарушениях от 30.12.2001 № 195-Ф3 // СЗ РФ. - 2002. - № 1 (ч. 1). - Ст. 1 (с послед. изменениями).
}

очевидная законодательная оплошность, однако она не является непреодолимым препятствием для осуществления прокурорами надзора в рассматриваемой сфере, поскольку, во-первых, ст. 52 Закона № 3-Ф3 дает возможность проведения прокурорских проверок во всем основным направлениям деятельности полиции, а, во-вторых, следует принимать во внимание универсальный характер положений ст. 21 Закона о прокуратуре, относящей к сфере «общего» надзора исполнение любых законодательных актов, кроме специально оговоренных законодателем (например, регулирующих специфику осуществления оперативнорозыскной или процессуальной деятельности органов полиции). Данное обстоятельство не означает, что по отношению к ст. 21 Закона о прокуратуре другие федеральные законодательные акты не могут содержать дополнительных характеристик предмета надзора за исполнением закона. Достаточно вспомнить, например, ст. 77 Федерального закона от 06.10.2003 № 131-Ф3 «Об общих принципах организации местного самоуправления в Российской Федерации "11, предоставляющую прокурору возможность осуществления надзора за исполнением органами местного самоуправления и их должностными лицами требований уставов муниципальных образований и муниципальных правовых актов.

В контексте реализации прокурорами ст. 21 Закона о прокуратуре следует отметить, что помимо проверок исполнения законодательных актов, непосредственно регулирующих деятельность полиции в рамках перечисленных выше основных направлений (например, Закон РФ от 11.03.1992 № 2487-1 «О частной детективной и охранной деятельности в Российской Федерации», федеральные законы от 10.12.1995 № 196-Ф3 «О безопасности дорожного движения», от 13.12.1996 № 150-Ф3 “Об оружии», от 24.06.1999 № 120-Ф3 «Об основах профилактики безнадзорности и правонарушений несовершеннолетних», от 31.05.2001 № 73-Ф3 "О государственной судебно-экспертной деятельности в Российской Федерации», от 06.04.2011 № 64-Ф3 «Об административном надзоре за лицами, освобожденными из мест лишения свободы» и др.), к сфере интересов органов прокуратуры относится исполнение в органах полиции законов, например, антикоррупционного характера, в том числе федеральных законов от 25.12.2008 № 273-Ф3 «О противодействии коррупции» и от 17.07.2009 № 172-Ф3 «Об антикоррупционной экспертизе нормативных правовых актов и проектов нормативных правовых актов». Особое

${ }^{11}$ СЗ РФ. - 2003. - № 40. - Ст. 3822 (с послед. изменениями). 
внимание, как и в деятельности других органов, прокурорами уделяется исполнению Федерального закона от 02.05.2006 № 59-Ф3 «О порядке рассмотрения обращений граждан Российской Федерации». Ну и, безусловно, необходимо принимать во внимание необходимость проверки исполнения положений самого Федерального закона "О полиции», особенно в части, регламентирующей права и обязанности, а также основания и порядок осуществления отдельных процедур, например, применения оружия, специальных средств и т.д.

Следует принимать во внимание еще одну сторону «общего» надзора, который, как отмечалось выше, осуществляется за исполнением законов, действующих на территории РФ. Согласно ч. 2 ст. 3 Закона № 3-Ф3 «Полиция в своей деятельности также руководствуется законами субъектов Российской Федерации по вопросам охраны общественного порядка и обеспечения общественной безопасности, изданными в пределах их компетенции». В этой связи в предмет надзора за исполнением законов полицией включается и исполнение органами и должностными лицами полиции соответствующих региональных законодательных актов. Пунктом 5 приказа Генерального прокурора РФ от 07.12.2007 № 195 «Об организации прокурорского надзора за исполнением законов, соблюдением прав и свобод человека и гражданина» ${ }^{12}$ прокурорам предписывается «установить постоянный надзор за исполнением действующих на территории Российской Федерации законов, включая не противоречащие федеральному законодательству законы субъектов Российской Федерации». Данное положение не является свидетельством расширения на ведомственном уровне предмета надзора, поскольку в Законе о прокуратуре нет оговорки о проведении прокурорами проверок исполнения исключительно законодательных актов федерального уровня. Более того, она фактически сужает предмет, поскольку за рамками ст. 71 и 72 Конституции РФ регионы вправе издавать собственные законы, которые, что вполне понятно, не будут противоречить федеральному законодательству. Поэтому по умолчанию исполнение таких законов также входит в предмет прокурорского надзора, но, естественно, не в рамках проверки деятельности полиции, поскольку вопросы обеспечения правопорядка и обеспечения общественной безопасности отнесены ст. 72 Конституции РФ к совместному ведению России и ее субъектов.

12 Законность. - 2008. - № 3 (с послед. изменениями).
Второй составляющей предмета «общего» надзора является соответствие закону правовых актов, издаваемых в системе МВД России и затрагивающих сферу деятельности полиции, в том числе документы, исходящие от Министра внутренних дел РФ. Например, только в 2012 г. согласно данным из формы статистического наблюдения «ОН» прокурорами выявлено в органах внутренних дел 81836 незаконных нормативных и ненормативных правовых актов, абсолютное большинство из которых по результатам опротестования отменены либо приведены в соответствие с законом (отклонено только 406 протестов $)^{13}$.

Несколько слов с учетом разделения функции прокурорского надзора на отрасли, имеющие самостоятельный предмет надзора, необходимо сказать о сфере соблюдения прав и свобод человека и гражданина, которая действительно упоминается в ст. 29 Закона о прокуратуре в контексте предмета надзора за исполнением законов при осуществлении оперативно-розыскной и процессуальной деятельности. С 1995 г. в рамках прокурорского надзора выделена самостоятельная отрасль - надзор за соблюдением прав и свобод человека и гражданина, которая позиционируется вне упоминания о соблюдении прав и свобод, рассматриваемого в ст. 29 Закона о прокуратуре $^{14}$. Ей посвящена гл. 2 раздела III Закона о прокуратуре и обособление ее было вызвано необходимостью вычленения правозащитной составляющей в надзорной деятельности прокуроров. По этому поводу профессор В.Б. Ястребов отмечал, что «выделение в Федеральном законе (о прокуратуре - прим. автора) надзора за соблюдением прав и свобод человека и гражданина в качестве самостоятельного направления деятельности прокуратуры - наглядное подтверждение существенного усиления в современных условиях ее правозащитной роли» ${ }^{15}$.

Хотя, следует отметить, что далеко не все известные ученые в сфере прокурорского надзора, позитивно оценивая необходимость выделения в предмете прокурорского надзора вопросов соблюдения

\footnotetext{
13 Приведенные цифры отражают, в том числе опротестованные постановления по делам об административных правонарушениях, на которые приходится основной объем дефектных правовых актов.

${ }^{14}$ См. подробнее об этом: Винокуров А.Ю. Соблюдение прав и свобод человека и гражданина как межотраслевой предмет прокурорского надзора // Законы России: опыт, анализ, практика. - 2011. - № 11.

15 См.: Комментарий к Федеральному закону «О прокуратуре Российской Федерации» / под ред. Ю.И. Скуратова. - М.: HOPMA, 1996. - C. 126.
} 
прав и свобод человека и гражданина, признают за рассматриваемой сферой право на существование В качестве самостоятельной надзорной отрасли. Например, профессор В.П. Рябцев предлагает объединить рассматриваемое направление с надзором за исполнением законов по причине их родственной «общенадзорной» природы ${ }^{16}$. В контексте настоящей статьи, не имея целью вступать в дискуссию с уважаемым автором, отметим, что ст. 26 Закона о прокуратуре, раскрывающая предмет надзора за соблюдением прав и свобод человека и гражданина, органично дополняет предмет надзора за законностью деятельности полиции, изложенный в ст. 52 Закона № 3-Ф3, в силу того, что полиция, как уже отмечалось нами выше, входит в структуру МВД России, то есть федерального органа исполнительной власти, а прокуратура призвана осуществлять надзор за соблюдением прав и свобод человека и гражданина, в том числе и такими органами и их должностными лицами. И именно по причине отсутствия у Следственного комитета РФ подобного статуса, как мы отметили выше, надзор за соблюдением его органами и должностными лицами прав и свобод человека и гражданина во внепроцессуальной сфере без особого на то указания законодателя невозможен.

И в этой связи следует признать правильной позицию, высказанную авторами выше названного комментария к Закону № 3-Ф3, о том, что «проверка соблюдения полицией прав и свобод граждан проводится прокурорами как по собственной инициативе, так и в связи с поступающими к ним жалобами и заявлениями ${ }^{17}$. Действительно, в отличие от надзора за исполнением законов, в рамках которого проверки проводятся прокурорами лишь на основании поступившей в органы прокуратуры информации о фактах нарушений законов, требующих принятия прокурором мер (п. 2 ст. 21 Закона о прокуратуре), при осуществлении надзора за соблюдением прав и свобод человека и гражданина прокурор не связан необходимостью наличия сведений о нарушающих права и свободы деяниях поднадзорных ему органов и лиц.

С учетом изложенного необходимо подчеркнуть, что надзор за исполнением законов полицией в контексте привязки к основным направлениям ее деятельности представляет собой комплексную деятельность, объединенную предметами прокурорского надзора

${ }^{16}$ См.: Рябцев В.П. Предмет надзора нуждается в дополнительной регламентации // Законность. - 2011. - № 3.

${ }_{17}$ См.: Аврутин Ю.Е., Булавин С.П., Соловей Ю.П., Черников В.В. Указ. раб. сразу в нескольких отраслях. Правильный в целом подход в этом отношении сделали авторы еще одного комментария к Закону № 3-ФЗ, которые отметили, что «применительно к деятельности полиции осуществляются следующие виды ${ }^{18}$ прокурорского надзора:

- надзор за исполнением законов... федеральными органами исполнительной власти, а также за соответствием законам издаваемых ими правовых актов;

- $\quad$ надзор за соблюдением прав и свобод человека и гражданина... федеральными органами исполнительной власти;

- надзор за исполнением законов органами, осуществляющими оперативно-розыскную деятельность, дознание и предварительное следствие (выделено нами - А.В.);

- надзор за исполнением законов администрациями мест содержания задержанных и заключенных под стражу (выделено нами - А.В.) ${ }^{19}$.

К сожалению, авторы этого комментария не избежали определенных ошибок, которые, возможно, являются следствием автоматического цитирования положений Закона о прокуратуре. Во-первых, согласно Закону № 3-ФЗ полиция не осуществляет предварительное следствие. Во-вторых, содержание лии, заключенных под стражу, достаточно давно изъято из сферы деятельности органов внутренних дел и является исключительной прерогативой учреждений Федеральной службы исполнения наказаний ${ }^{20}$. Но в целом ориентирование на ст. 32 Закона о прокуратуре, закрепляющую предмет прокурорского надзора в уголовно-исполнительной сфере, включая вопросы законности содержания задержанных лиц в изоляторах временного содержания подозреваемых и обвиняемых органов внутренних дел, входящих в структуру полиции, нужно признать правильным.

Аналогичный рассмотренному подход, в том числе с перечислением сфер деятельности, не входящих в предмет надзора за исполнением законов полицией (предварительное следствие, содержание заключенных под стражу), избран и в комментарии, подго-

\footnotetext{
18 По сложившейся в прокурорской науке классификации речь идет об отраслях надзора.

19 Барсуков С.И., Борисов А.Н. Комментарий к Федеральному закону «О полиции» (постатейный). - М.: «Деловой двор», 2011.

20 Правда, следуетотметить, чтонеотвечающеетребованиямзакона словосочетание «заключенных под стражу лиц, находящихся в изоляторах временного содержания. ..» используется в подп. «П» п. 1 Указа Президента РФ от 01.03.2011 № 250 «Вопросы организации полиции» // СЗ РФ. - 2011. - № 10. - Ст. 1336.
} 
товленном А.П. Рыжаковым²1. Однако данный автор предпринял попытку сформулировать комплексно сущность прокурорского надзора в рассматриваемой сфере. Он пишет, что «надзор за законностью деятельности полиции - это осуществляемая от имени государства деятельность Генерального прокурора России и подчиненных ему прокуроров, направленная на обеспечение точного и единообразного исполнения всех законов РФ на территории всей страны полицией, ее подразделениями и сотрудниками путем принятия мер к выявлению, своевременному устранению любых нарушений законов сотрудниками полиции и привлечению виновных к ответственности» 22 .

Приведенная формулировка, хотя она, судя по всему, носит описательный характер и не претендует в силу этого на вклад в теорию прокурорского надзора, тем не менее, заслуживает внимания, поскольку автор абсолютно правильно не пытался сделать заведомо невыполнимое - консолидировать в одном предложении воедино предметы сразу четырех названных выше надзорных отраслей. В качестве дополнения к этой дефиниции отметим, что едва ли речь должна идти о проверке прокурорами всех законов, а, кроме того, с учетом высказанных нами выше умозаключений, прокуроры вправе проверять исполнение органами и должностными лицами законов не только Российской Федерации, но и ее субъектов, изданных по вопросам охраны общественного порядка и обеспечения общественной безопасности.

Вместе с тем полагаем, что наиболее логичным подходом к формулированию предмета надзора за исполнением законов полицией было бы изложение его в классической для прокурорской науки трактовке посредством упоминание об основных направлениях деятельности, например, в следующей редакции:

«предметом надзора за исполнением законов полицией является соблюдение Конституции Российской Федерации, исполнение действующих на территории Российской Федерации законов и соблюдение прав и свобод человека и гражданина органами полиции и их должностными лицами при осуществлении ими основных направлений деятельности, а также соблюдение должностными лицами органов полиции установленных законом порядка и условий прохождения службы».

21 Рыжаков А.П. Постатейный комментарий к Федеральному закону «О полиции» от 7 февраля 2011 г. № 3-Ф3. - М.: Московская финансово-промышленная академия, 2011.

22 Там же.
Завершая изложение специфики осуществления прокурорского надзора в рассматриваемой сфере, хотелось бы отметить, что важное значение для его правильной организации и осуществления имеют ряд организационно-распорядительных документов Генерального прокурора РФ. В первую очередь, с учетом неоднородности системы прокуратуры, а также наличия в самой системе МВД России подразделений на транспорте (железнодорожном, водном и воздушном) приказ от 07.05.2008 № 84 «О разграничении компетенции прокуроров территориальных, военных и других специализированных прокуратур» определяет пределы осуществления надзора, в том числе за исполнением законов полицией, прокурорами субъектов РФ и подчиненными им территориальными прокурорами районного звена, а также прокурорами по надзору за исполнением законов на особо режимных объектах, природоохранными прокурорами ${ }^{23}$, Волжским межрегиональным природоохранным прокурором и подчиненными ему природоохранными прокурорами, региональными транспортными прокурорами и подчиненными им межрайонными транспортными прокурорами.

Применительно к отдельным отраслям надзора и определенным направлениям деятельности при осуществлении проверок органов полиции прокуроры руководствуются приказами Генерального прокурора РФ от 06.09.2007 № 137 «Об организации прокурорского надзора за процессуальной деятельностью органов дознания», от 07.12.2007 № 195 «Об организации прокурорского надзора за исполнением законов, соблюдением прав и свобод человека и гражданина», от 15.02.2011 № 33 «Об организации прокурорского надзора за исполнением законов при осуществлении оперативно-розыскной деятельности» и др.

Таким образом, надзор за исполнением законов полицией представляет собой комплексное направление прокурорского надзора, ориентированное на обеспечение законности при осуществлении полицией возложенных на нее основных направлений деятельности. Безусловно, рассматриваемая проблематика имеет серьезные монографические перспективы, однако в рамках настоящей статьи полагаем возможным ограничиться изложенным материалом, не вдаваясь в детализацию надзорного процесса.

${ }^{23}$ В структуре прокуратур городов Москвы и СанктПетербурга созданы также прокуратуры по надзору за исполнением законов на метрополитене, где, как известно, также функционируют специализированные подразделения органов внутренних дел. 


\section{Библиографический список:}

1. Аврутин Ю.Е., Булавин С.П., Соловей Ю.П., Черников В.В. Комментарий к Федеральному закону «О полиции» (постатейный). - М.: «Проспект», 2012.

2. Барсуков С.И., Борисов А.Н. Комментарий к Федеральному закону «О полиции» (постатейный). - М.: «Деловой двор», 2011.

3. Винокуров А.Ю. Объекты и субъекты прокурорского надзора: проблемы законодательной идентификации // Вестник Академии Генеральной прокуратуры Российской Федерации. - 2011. - № 3 (23).

4. Винокуров А.Ю. Следственный комитет как объект прокурорского надзора // Вестник Академии Генеральной прокуратуры РФ. - 2011. - № 1 (21).

5. Винокуров А.Ю. Соблюдение прав и свобод человека и гражданина как межотраслевой предмет прокурорского надзора // Законы России: опыт, анализ, практика. - 2011. - № 11.

6. Комментарий к Федеральному закону «О прокуратуре Российской Федерации» / под ред. Ю.И. Скуратова. M.: HOPMA, 1996.

7. Рыжаков А.П. Постатейный комментарий к Федеральному закону «О полиции» от 7 февраля 2011 г. № 3-Ф3. М.: Московская финансово-промышленная академия, 2011.

8. Рябцев В.П. Предмет надзора нуждается в дополнительной регламентации // Законность. - 2011. - № 3.

\section{References (transliteration):}

1. Avrutin Yu.E., Bulavin S.P., Solovey Yu.P., Chernikov V.V. Kommentariy k Federal'nomu zakonu «O politsii» (postateynyy). - M.: «Prospekt», 2012.

2. Barsukov S.I., Borisov A.N. Kommentariy k Federal'nomu zakonu «O politsii» (postateynyy). - M.: «Delovoy dvor», 2011.

3. Vinokurov A.Yu. Ob’ekty i sub'ekty prokurorskogo nadzora: proble-my zakonodatel'noy identifikatsii // Vestnik Akademii General'noy prokuratury Rossiyskoy Federatsii. — 2011. — № 3 (23).

4. Vinokurov A.Yu. Sledstvennyy komitet kak ob'ekt prokurorskogo nadzora // Vestnik Akademii General'noy prokuratury Rossiyskoy Federatsii. - 2011. - № 1 (21).

5. Vinokurov A.Yu. Soblyudenie prav i svobod cheloveka i grazhdanina kak mezhotraslevoy predmet prokurorskogo nadzora // Zakony Rossii: opyt, ana-liz, praktika. - 2011. - № 11.

6. Kommentariy k Federal'nomu zakonu «O prokurature Rossiyskoy Federatsii» / pod red. Yu.I. Skuratova. - M.: NORMA, 1996.

7. Ryzhakov A.P. Postateynyy kommentariy k Federal'nomu zakonu «O politsii» ot 7 fevralya 2011 g. № 3-FZ. - M.: Moskovskaya finansovo-promyshlennaya akademiya, 2011.

8. Ryabtsev V.P. Predmet nadzora nuzhdaetsya v dopolnitel'noy reglamen-tatsii // Zakonnost'. — 2011. - № 3. 